\title{
OS LICENCIAMENTOS URBANÍSTICOS: UMA BREVE VISÃO SOBRE O DIREITO PORTUGUÊS
}

\author{
URBAN DEVELOPMENT LICENSES: A BRIEF OVERVIEW OF THE PORTUGUESE LAW
}

Fernanda Paula Oliveira*

\begin{abstract}
Resumo:
O presente texto visa apresentar a forma como os procedimentos de controlo administrativo de operações urbanísticas tem evoluído no ordenamento jurídico português, mostrando a forma como o legislador tem procurado dotar tais procedimentos de maior simplificação. Efetivamente, e como aqui se analisa, a busca por uma maior simplificação dos procedimentos de controlo da realização de operações urbanísticas sempre foi uma preocupação do legislador português, tendo-o traduzido nas múltiplas alterações legislativas ao regime que regula esta atividade e que é, atualmente, o Regime Jurídico da Urbanização e Edificação.

Palavras-chave: Controlos administrativos. Licenças urbanísticas. Comunicações prévias. Simplificação administrativa.
\end{abstract}

\begin{abstract}
:
This text aims to present the way in which the procedures for administrative control of urban operations have evolved in the Portuguese legal system, showing how the legislator has sought to provide such procedures with greater simplification. Effectively, and as discussed in this text, the search for greater simplification of the procedures for controlling urban operations has always been a concern of the Portuguese legislation.
\end{abstract}

Keywords: Administrative controls. Town planning licenses. Prior communications. Administrative simplification.

1. Operações urbanísticas e seu controlo pela administração: considerações iniciais e razão de ordem

i. $\quad$ Considerações iniciais

Em Portugal as operações de intervenção urbanística no território são designadas genericamente de operações urbanísticas, conceito que abrange todas as operações materiais de urbanização, de edificação, de utilização dos edifícios ou de utilização dos solos, desde que, neste último caso, para fins não exclusivamente agrícolas, pecuários, florestais, mineiros ou de abastecimento público de água.

* $\quad$ Professora da Faculdade de Direito da Universidade de Coimbra. 
Neste conceito incluem-se:

- as obras de urbanização: obras de criação e remodelação de infraestruturas destinadas a servir diretamente os espaços urbanos ou as edificações, designadamente arruamentos viários e pedonais, redes de esgotos e de abastecimento de água, eletricidade, gás e telecomunicações, e ainda espaços verdes e outros espaços de utilização coletiva;

- as operações de loteamento urbano: ações que têm por objeto ou por efeito a constituição de um ou mais lotes destinados, imediata ou subsequentemente, à edificação urbana e que resulte da divisão de um ou vários prédios ou do seu reparcelamento;

- os trabalhos de remodelação de terrenos: operações que implicam a destruição do revestimento vegetal, a alteração do relevo natural e das camadas de solo arável ou o derrube de árvores de alto porte ou em maciço para fins não exclusivamente agrícolas, pecuários, florestais ou mineiros;

- as obras de edificação, sejam elas de nova construção ou de intervenção em edifícios existentes, podendo, neste caso, traduzir-se em:

- obras de conservação: destinadas a manter uma edificação nas condições existentes à data da sua construção, reconstrução, ampliação ou alteração, designadamente as obras de restauro, reparação ou limpeza;

- obras de reconstrução: obras de construção subsequentes à demolição, total ou parcial de uma edificação existente, destinadas a reconstituila;

- obras de alteração: obras de modificação das características físicas de uma edificação existente, ou sua fração;

- obras de ampliação: obras de que resulta o aumento da área de implantação, da área total de construção, da altura da fachada ou do volume de uma edificação;

- obras de demolição: obras de destruição, total ou parcial, de uma edificação existente.

Também a utilização dos edifícios e a utilização dos solos para fins não agrícolas, pecuários, florestais ou mineiros integram este conceito.

Porque as operações que acabámos de enumerar podem contender com importantes interesses públicos (como o correto ordenamento do território, o património cultural, o ambiente, etc.), as mesmas encontram-se condicionadas por normas legais e regulamentares (incluindo as de planeamento do território) e estão, por 
isso, tradicionalmente (e por regra) sujeitas a controlos administrativos preventivos, normalmente da responsabilidade dos órgãos municipais, procedimentos esses que se destinam a aferir se a concreta operação urbanística que o promotor pretende levar a cabo cumpre as referidas condicionantes legais e regulamentares e, cumprindo-as, permitir a sua concretização.

Podemos designar estes procedimentos de controlo administrativo prévio das operações urbanísticas genericamente de "licenciamentos urbanísticos", que correspondem a uma típica função da administração: a função de controlo público de atividades privadas com potencial de risco para o interesse público.

\section{ii. $\quad$ Razão de ordem}

De modo a melhor compreender os procedimentos de licenciamento urbanístico no ordenamento jurídico Português, iniciaremos o nosso percurso caraterizando, desde logo e de forma genérica, esta tradicional função administrativa de controlo prévio de atividades privadas e referindo a sua evolução nos últimos anos, evolução essa que passou em Portugal, adiantamo-lo desde já, pela perda de centralidade desta atividade no âmbito das novas tendências de simplificação, de neoregulação, de privatização e de economização da ação administrativa.

Vista essa evolução em geral, analisaremos, num segundo momento, a forma como essa evolução ocorreu no âmbito dos licenciamentos urbanísticos, área onde as exigências de simplificação se fazem sentir com maior acuidade. Com efeito, envolvendo os projetos urbanísticos, por norma, grandes investimentos, facilmente se conclui que o tempo da Administração (no controlo destas atividades) raramente está adequado ao tempo dos privados: aquela necessita de prazos razoáveis para efetuar tal controlo; para os privados, tais prazos (frequentemente demasiado longos) são um custo de contexto, por vezes excessivamente oneroso que tem de enfrentar. Efetivamente, e como analisaremos, a busca por uma maior simplificação dos procedimentos de controlo da realização de operações urbanísticas sempre foi uma preocupação do legislador português, tendo-o traduzido nas múltiplas alterações legislativas ao regime que regula esta atividade e que é, atualmente, o Regime Jurídico da Urbanização e Edificação.

Analisada esta evolução legislativa no âmbito dos licenciamentos urbanísticos, será feita, num terceiro momento, tomando como referência as obras de edificação, uma breve análise do procedimento de licenciamento (sua tramitação e caraterísticas) e da comunicação prévia de operações urbanísticas (uma nova forma, simplificada, de controlo destas atividades). Quanto a esta serão, no final, realçadas as vantagens da sua aplicação quanto estão em causa operações urbanísticas, mas também as suas especiais dificuldades e desvantagens. 
2. Controlo administrativo de atividades privadas em geral: evolução

i. A forma de atuação tradicional da Administração - o modelo de regulação administrativa tradicional - assenta num modelo de regulação de polícia, que se refere à atividade administrativa de ordenação e controlo com vista à tutela e à realização de certos bens, valores ou interesses de importância coletiva, consagrados, em regra, na própria Constituição - v.g., o correto ordenamento do território, o ambiente, o património cultural -, de modo a que se possa atingir e salvaguardar um certo equilíbrio social conforme com o bem comum ou o interesse público.

Trata-se de um modelo de regulação que foi particularmente utilizado no Estado de direito social e democrático, fruto do progressivo crescimento das funções estaduais, o que implicou uma intervenção pública direta mais alargada sobre a sociedade.

Esta regulação de polícia tanto abrange instrumentos de regulação normativa [assente na existência de múltiplas normas (públicas), legais ou regulamentares, que estabelecem as "condições de segurança" da comunidade] como de regulação administrativa (baseada na adoção de medidas administrativas para aplicação das soluções normativas, quer por via de sistemas de controlo público prévio de atividade privadas (autorizações, licenças) quer da fiscalização ou inspeção do seu cumprimento pelos particulares e na aplicação de sanções, caso tal cumprimento não ocorra). Trata-se de um típico sistema de comand e control.

ii. Uma das formas tradicionais da regulação administrativa prende-se, como acabámos de referir, com a função de controlo prévio de atividades privadas. Referimonos às atividades privadas que não são livres, mas, antes, condicionadas ou sujeitas a proibição relativa por lei ou outro ato normativo ${ }^{1}$ por poderem contender com interesses públicos que devem ser salvaguardados (como o ordenamento do território, o património cultural, a saúde pública, a segurança, o ruído, o ambiente). Nestes casos, a função do controlo administrativo prévio é a de remover tal condicionamento ou proibição, o que é feito pela figura tradicional da autorização que, deste modo, se apresenta como um dos principais instrumentos de regulação administrativa.

Nas situações em que estão em causa atividades privadas em regra proibidas [proibição (repressiva) com reserva de licença], a autorização é a situação excecional (corresponde ao ato que remove a proibição) - autorização-licença ou autorização-dispensa -; tratando-se de atividades privadas preventivamente proibidas [proibição (preventiva)

Tirando as atividades privadas livres e as atividades privadas absolutamente proibidas, as restantes tanto podem ser atividades privadas preventivamente proibidas (por lei) - o que significa que podem ser levadas a cabo se cumprirem determinadas condições -, como atividades privadas em regra proibidas (por lei) - o que significa que não podem ser levadas a cabo, a não ser que cumpram determinadas condições. 
com reserva de autorização], a autorização é o desfecho normal do procedimento já que a intenção da lei não é afastar o desenvolvimento da atividade privada: a intenção é que a Administração verifique previamente o cumprimento de determinados requisitos ou condições que a lei fixa para que a atividade se possa desenvolver sem perigo ou risco (autorização permissiva). ${ }^{2}$

O facto de a autorização configurar um controlo preventivo por parte da Administração, não exclui a existência de controlos sucessivos: a autorização origina uma relação jurídica continuada entre a Administração pública e a entidade autorizada, donde o controlo sucessivo visar verificar se a atividade está a ser desenvolvida nos termos autorizados e/ou se se mantêm os requisitos exigidos para o exercício da atividade.

Do que referimos decorre que esta forma de atuação administrativa típica do modelo de regulação de polícia (a autorização) ocorre quando a lei determina que uma dada atividade privada não pode ser desenvolvida antes ou independentemente de controlo prévio por parte da Administração sobre a verificação de determinados requisitos que a lei exige, o que obriga o interessado no exercício da atividade a dar início a um procedimento administrativo no âmbito do qual a Administração tem o dever de decidir: se a decisão for favorável (deferimento), a mesma atesta a verificação dos requisitos (autorização). ${ }^{3}$

A autorização proferida pela Administração corresponde, assim, a um ato administrativo que põe termo a um procedimento, iniciado ou desencadeado por um dado particular interessado na obtenção de uma decisão oficial que permita o exercício da sua atividade.

Por sua vez, a Administração tem a responsabilidade pública de proceder caso a caso, a um juízo de adequação entre a pretensão do particular e a normatividade jurídica vigente, ou seja, o órgão administrativo desenvolve, no exercício da função pública autorizativa, uma ponderação concreta entre o interesse particular e o interesse público relevante (realizando também uma síntese entre a liberdade e a segurança). E, em função dessa ponderação, tem o dever de decidir o requerimento do interessado.

iii. Existe hoje uma tendência para a simplificação dos controlos administrativos prévios ao exercício de atividades privadas, simplificação que, para determinadas atividades de menor risco pode mesmo consubstanciar-se na substituição do

2 Qualquer destes tipos de autorização correspondem a procedimentos de controlo preventivo (ex ante, i.é, antes do início) das atividades privadas: a autorização visa preventivamente dar à autoridade administrativa uma oportunidade de verificar o cumprimento das exigências fixadas na lei (as quais, por sua vez, visam salvaguardar interesses públicos).

3 Esta autorização pode surgir pela via do silêncio, o que sucederá se a lei ficcionar que a falta de decisão vale como deferimento (deferimento tácito). Se não o fizer, a falta de decisão corresponderá simplesmente, ao incumprimento de dever de decidir ao qual o interessado pode reagir pelas vias adequadas, incluindo a via judicial. 
princípio da autoridade pública pelo princípio da autorresponsabilização dos particulares: em vez de mecanismos de controlo assentes em procedimentos de autorização, criamse formas de controlo prévio da responsabilidade dos interessados em desenvolver a atividade que tem algum potencial de perigo e cujo desenvolvimento se mantém, por isso, dependente da observância de requisitos fixados na lei. ${ }^{4}$

Note-se que, ausência de controlo administrativo prévio não significa ausência de controlo administrativo; apenas que a Administração passa a desenvolver um controlo sucessivo (controlo ex post) de natureza repressiva (inspeções, fiscalizações) de atividades privadas livremente iniciadas.

E note-se, também, que ausência de controlo administrativo prévio não significa liberalização da atividade: esta continua sujeita a um conjunto de requisitos e condições legal ou regulamentarmente impostos para o acesso e exercício de atividades privadas; o que ocorre é uma diminuição ou abolição do controlo público prévio do cumprimento desses requisitos e pressupõe, concomitantemente, um aumento da regulamentação (definição mais objetiva e até mais exigências e requisitos) para o exercício da atividade.

Trata-se de um novo modelo que não implica a abolição de controlos públicos: eles passam a ser posteriores ou sucessivos, isto é, efetuados em princípio já com as atividades em desenvolvimento.

A eliminação de controlos administrativos prévios corresponde, assim, a uma medida de simplificação e de economização: de simplificação, na medida em que pressupõe uma modificação quantitativa do procedimento administrativo (redução do número de tarefas, designadamente procedimentais, a cargo da Administração Pública), por forma a garantir sua atuação, na sua globalidade, mais racional e menos burocrática; de economização porque provoca um decréscimo do montante global dos "custos de contexto": custos que os agentes económicos têm de suportar na sequência do seu relacionamento com a Administração, "internalizados", assim, no contexto do processo produtivo, v.g., custo em termos de tempo, custos monetário para cumprimento de formalidades obrigatórias, etc. ${ }^{5}$

\footnotetext{
4 Segundo Pedro Gonçalves (2005, p. 186, 201 et seq.), a entrega de funções de controlo aos particulares constituiu mais uma peça no processo de reconfiguração ou redefinição do papel e das funções do Estado, ilustrando uma estratégia de substituição de tradicionais responsabilidades públicas de execução por novas responsabilidades públicas de garantia e de "controlo (público) do controlo privado". Daí não resulta, segundo o Autor, um abandono do Estado das suas atribuições de controlo e de verificação da legalidade das ações privadas; apenas a renuncia a certas competências que exercia no âmbito dessas atribuições.

5 Precisamente um dos "custos de produção" é a morosidade detetável na atuação administrativa no do seu relacionamento ou na sua resposta aos particulares (v.g., aquando da autorização de uma determinada atividade que o particular pretende iniciar).
} 
É neste âmbito que se integram as figuras da mera comunicação prévia e da comunicação prévia com prazo, as quais foram introduzidas no ordenamento jurídico português pelo Decreto-Lei n. ${ }^{\circ}$ 92/2010, de 26 de julho, que transpôs para o nosso ordenamento jurídico a «Diretiva de Serviços» ${ }^{6}$ e onde a mera comunicação prévia é definida como "uma declaração efetuada pelo prestador de serviços necessária ao início da atividade, que permita o exercício da mesma imediatamente após a sua comunicação à autoridade administrativa", e a comunicação prévia com prazo é enunciada como "uma declaração efetuada pelo prestador de serviços necessária ao início da atividade, que permita o exercício da mesma quando a autoridade administrativa não se pronuncie após o decurso de um determinado prazo".

Há, como se pode observar, diferenças significativas entre estas duas figuras. A mera comunicação prévia não tem a natureza de uma permissão administrativa: trata-se, antes, do cumprimento de um dever de comunicar à Administração a realização de uma atividade privada, por exemplo, para efeitos de pagamento de taxas devidas, de eventual fiscalização ulterior do cumprimento de requisitos ou outros efeitos semelhantes; não depende, nem exige qualquer reação da Administração para que a atividade em questão possa ser iniciada ou exercida, embora não dispense o particular de cumprir as regras previamente definidas pela Administração, devendo inclusive naquela comunicação responsabilizar-se por isso.

Por sua vez, a comunicação prévia com prazo depende de uma certificação ou de um ato da Administração, o qual tem, na verdade, a natureza de uma permissão (autorização) administrativa, menos exigente do que uma licença ou uma autorização, mas mais exigente do que um mero registo, por exemplo, quanto ao prazo de resposta da Administração, à possibilidade de recusa ou ao número e diversidade de documentos instrutórios exigidos.

Resulta óbvio desta comparação que é a figura da mera comunicação prévia que corresponde, de um modo mais impressivo e efetivo, a uma medida de simplificação e de eliminação dos custos de contexto: uma vez feita a comunicação, a atividade inicia-se de imediato, ocorrendo uma renúncia à decisão administrativa: em vez de proibição com reserva de autorização, passamos a ter uma proibição com reserva de comunicação - a Administração não profere qualquer decisão passível de oficializar a juridicidade daquela atuação privada. ${ }^{7}$

6 Diretiva n. ${ }^{\circ}$ 2006/123/CE do Parlamento Europeu e do Conselho de 12 de dezembro de 2006 relativa aos serviços no mercado interno.

7 Concordamos com a doutrina segundo a qual "a substituição de procedimentos de autorização por procedimentos de comunicação de início de atividade está associada a uma estratégia de privatização material e de reforço das responsabilidades dos particulares", o que "não equivale à transferência para os particulares do poder público de emitir a licença: o Estado renuncia à decisão administrativa, mas não 
As figuras da mera comunicação prévia e da comunicação prévia com prazo vieram a ter consagração expressa no artigo $134 .^{\circ}$ do Código do Procedimento Administrativo [aprovado pelo Decreto-Lei n. ${ }^{\circ} 4 / 2015$, de 7 de janeiro, doravante CPA] ${ }^{8}$ e a ser adotado em diplomas especiais que regulam atividades tradicionalmente sujeitas a controlo prévio administrativo: no Regime Jurídico de Acesso e Exercício de Atividades de Comércio, Serviços e Restauração; no Regime Jurídico relativo à atividade industrial (Sistema de Indústria Responsável); no regime das atividades de organização de campos de férias; no regime referente ao aluguer de veículos de passageiros sem condutor; no regime relativo à produção de energia elétrica em regime especial; no regime da instalação e funcionamento do Alojamento Local, entre outros.

E também, como melhor veremos nos pontos que se seguem, no âmbito da atividade de urbanização e edificação (o tradicional domínio do licenciamento urbanístico).

3. Controlo administrativo das "operações urbanísticas": evolução dos "licenciamentos" urbanísticos

Refira-se, antes de mais, que os "licenciamentos urbanísticos", isto é, os procedimentos de controlo prévio das operações urbanísticas, são objeto, em Portugal, da disciplina jurídica que consta do Regime Jurídico da Urbanização e Edificação (RJUE). ${ }^{9}$ Estes procedimentos têm vindo a sofrer, ao longo dos anos, uma evolução legal e doutrinária que importa aqui reter nos seus momentos mais relevantes. Vejamo-la, numa breve síntese.

investe os particulares do poder (público) de tomar essa decisão". (GONÇALVES, 2005, p. 207).

8 Determina este artigo: "I - A lei pode prever que a produção de determinados efeitos jurídicoadministrativos e o seu aproveitamento pelo interessado não dependa da emissão de um ato administrativo procedimentalizado, mas resulte, de forma imediata, da mera comunicação prévia pelo interessado do preenchimento dos correspondentes pressupostos legais e regulamentares. 2 -A lei também pode estabelecer um regime de comunicação prévia com prazo, determinando que a comunicação prévia do interessado só produza os efeitos visados se o órgão competente não se pronunciar em sentido contrário dentro de determinado prazo. 3 - Nas situações de comunicação prévia com prazo, a ausência de pronúncia do órgão competente não dá origem a um ato de deferimento tácito, mas habilita o interessado a desenvolver a atividade pretendida, sem prejuizo dos poderes de fiscalização da Administração e da possibilidade de esta utilizar os meios adequados à defesa da legalidade".

9 Aprovado pelo Decreto-Lei n. ${ }^{\circ}$ 555/1999, de 16 de dezembro. Este diploma foi objeto de várias alterações. Aquelas que tiveram maior relevo na evolução do tipo de controlo das operações urbanísticas foram as efetuadas pelo Decreto-Lei n. ${ }^{\circ}$ 177/2001, de 4 de junho, pela Lei n. ${ }^{\circ}$ 60/2007, de 4 de setembro e pelo Decreto-Lei n. ${ }^{\circ}$ 136/2014, de 9 de setembro. 


\subsection{Até à Lei n. ${ }^{\circ}$ 60/2007, de 4 de setembro}

i. Antes da entrada em vigor do RJUE, o procedimento de controlo preventivo a que se encontravam sujeitas as operações urbanísticas sempre foi o procedimento de licenciamento, não obstante a tramitação deste variasse já então em função, designadamente, do grau de densidade do instrumento urbanístico em vigor na respetiva área.

ii. Com a versão inicial do RJUE em 1999, o legislador veio, no que ao controlo preventivo das operações urbanísticas diz respeito, assentar na distinção básica entre o procedimento de licenciamento (de tramitação mais complexa) e o procedimento de autorização, (mais simplificado): os critérios definidores do âmbito de cada um destes procedimentos assentavam na distinta densidade de planeamento vigente na área para a qual era requerida a realização da operação urbanística e no tipo de operação a realizar. Assim, o procedimento simplificado de autorização utilizar-se-ia quando os parâmetros da decisão estivessem definidos com precisão num plano concreto ou num prévio ato da Administração (por exemplo, uma licença de loteamentos) ou quando a operação a realizar tivesse menor relevância urbanística (como as obras de reconstrução). O procedimento de licenciamento teria lugar nas restantes situações.

Ou seja, a autorização era o ato de controlo preventivo exigido para aquelas situações em que, por as regras e os parâmetros de apreciação dos projetos se encontrarem já definidos com bastante precisão em prévio instrumento (de planeamento ou de gestão urbanística), se podia afirmar que a posição jurídica do interessado estava já bastante densificada pelo que, desde que o projeto apresentado não contrariasse aquelas normas, o particular requerente teria direito à autorização. Concomitantemente, pela mesma razão, o poder de apreciação da Administração municipal estava, nestes casos, mais vinculado.

Por sua vez, a licença seria o ato de controlo preventivo mobilizável nas situações em que, por tais regras e critérios não se encontrarem ainda definidos ou não estarem definidos com precisão, a lei deixava uma maior margem de discricionariedade à Administração na apreciação dos projetos concretos, pelo que não se poderia dizer que o particular tivesse automaticamente um direito à licença, na medida em que a questão de saber se o projeto apresentado estava ou não conforme ao ordenamento urbanístico vigente necessitava da intervenção de um juízo intermediador (entre a lei e a situação concreta) da Administração.

Assim, e de acordo com a redação inicial do RJUE, os procedimentos de licenciamento e de autorização distinguir-se-iam pela diferente densidade de controlo preventivo e pelo diferente grau de concretização da posição subjetiva do particular: na autorização, a posição subjetiva deste estaria mais concretizada (por se encontrar predefinida em prévio ato administrativo ou instrumento de planeamento concreto) e, 
por isso, haveria uma menor intensidade (e, portanto, maior vinculação) do controlo preventivo por parte dos órgãos municipais competentes; ${ }^{10}$ na licença a posição subjetiva do particular estaria menos concretizada (por não ser enquadrada por prévio ato ou plano antecipadores da pretensão), motivo pelo qual a intensidade de controlo seria maior por parte dos órgãos municipais competentes, isto é, estes estariam, na apreciação dos projetos, dotados de maior discricionariedade).

iii. O Decreto-Lei n. ${ }^{\circ}$ 177/2001 (primeira alteração ao RJUE), que pretendia tão-só proceder a alguns "acertos" na figura da autorização, acabou não só por colocar em causa a sua própria subsistência enquanto figura autónoma em face da licença, como ainda por afetar a distinção concetual desta relativamente ao procedimento de licenciamento. E isto porque o legislador acabou por reconhecer que a Administração gozava dos mesmos poderes (discricionários) na apreciação dos projetos quer no procedimento de autorização quer no de licenciamento, motivo pelo qual deixava de se poder afirmar estar a posição jurídica do interessado mais consolidada naquela do que nesta.

Em todo o caso, este diploma manteve a distinção entre licença e autorização, acabando esta por se traduzir somente (e já não era pouco) num procedimento mais célere, quer porque se exigia que a apreciação de todos os projetos fosse feita em simultâneo quer porque não havia lugar, no seu âmbito, a consulta a entidades exteriores ao município, traduzindo-se, por isso, num procedimento de "licenciamento", mas mais simples ou expedito.

3.2. Os procedimentos de controlo preventivo após a Lei n. ${ }^{\circ} 60 / 2007$, de 4 de setembro até ao Decreto-Lei n. ${ }^{\circ} 136 / 2014$, de 9 de setembro

A Lei n. ${ }^{\circ}$ 60/2007, de 4 de setembro veio redelimitar o âmbito de aplicação dos procedimentos de controlo preventivo das operações urbanísticas, visando, por um lado, objetivos de simplificação procedimental e, por outro lado, objetivos de eliminação de controlo nas situações em que, na ótica do legislador, este manifestamente se não justificava.

A concretização do primeiro daqueles desígnios traduziu-se na quase extinção do procedimento de autorização - que passou a ficar limitado à utilização dos edifícios ou suas frações autónomas, bem como às alterações de utilização dos mesmos e a sua substituição, praticamente na íntegra, pelo procedimento de comunicação prévia, tendo-se, no entanto, mantido, na distinção genérica entre as operações que deviam ficar

10 Esta diminuição do controlo preventivo da operação urbanística traduzir-se-ia, simultaneamente, num aumento da responsabilidade dos particulares e dos autores do projeto e num maior controlo a posteriori, em matéria de vistoria e de fiscalização. 
sujeitas a licença e as que deviam ser submetidas a comunicação prévia, os critérios em que assentava a distinção entre procedimentos de licença e procedimentos de autorização na versão originária do diploma.

Assim, o que passa a caracterizar o âmbito de aplicação da comunicação prévia (tal como o que caracterizava anteriormente o âmbito de aplicação das autorizações) era, tendencialmente, o facto de em causa estarem operações urbanísticas que ocorrem em áreas para as quais os parâmetros aplicáveis se encontram previamente definidos com algum grau de precisão quer em instrumento de planeamento (plano de pormenor com determinadas características) quer em ato administrativo (que tenha aprovado uma operação de loteamento ou uma informação prévia muito precisa) quer, ainda, na situação fáctica existente (zona urbana consolidada).

De acordo com o artigo 36. ${ }^{\circ}$ do RJUE, "no prazo de 20 dias a contar da entrega da comunicação e demais elementos a que se refere o artigo anterior, o presidente da câmara municipal, com faculdade de delegação nos vereadores, deve rejeitar a comunicação quando verifique que a obra viola as normas legais e regulamentares aplicáveis", determinado o artigo $36 .^{\circ}$-A (com a epígrafe, ato administrativo) "1 Decorrido o prazo previsto no artigo anterior sem que a comunicação prévia tenha sido rejeitada, é disponibilizada no sistema informático previsto no artigo $8 .^{\circ}$-A a informação de que a comunicação não foi rejeitada, o que equivale à sua admissão. 2 - Na falta de rejeição da comunicação prévia, o interessado pode dar início às obras, efectuando previamente o pagamento das taxas devidas através de autoliquidação".

Tendo em consideração o que se referiu supra relativamente às figuras da comunicação prévia, facilmente se percebe que a comunicação que ficou consagrada no RJUE com a Lei n. ${ }^{\circ}$ 60/2007, correspondia a uma comunicação prévia com prazo, na medida em que era fixado um lapso temporal para que a Administração se opusesse expressamente à pretensão, caso esta não cumprisse as exigências legais e regulamentares aplicáveis. E caso tal oposição não ocorresse naquele lapso temporal, formar-se-ia, ex lege, um ato de admissão da pretensão do interessado, que poderia, assim, iniciar a sua atividade.

Desta forma, de modo a obstar à formação de um ato de admissão, a Administração tinha de praticar o ato contrário no prazo previsto para o efeito, correspondendo este ato (designado de rejeição) ao exercício de um "direito de veto", fundamentado e certo, por parte da Administração.

Com esta configuração, a admissão da comunicação prévia, ainda que não expressamente declarada, assumia a natureza de ato administrativo, não apenas por razões formais (cfr. a epígrafe do artigo 36. ${ }^{\circ}$-A, que assim o designava), mas também pela equiparação que a mesma merecia relativamente ao regime da licença em vários normativos legais [invalidade e nulidade do ato de admissão (artigos $67 .{ }^{\circ}$ e $68 .^{\circ}$ ), 
revogabilidade (artigo $73 .^{\circ}$ ), declaração de caducidade (artigo $71^{\circ}$ ), renovação (artigo 72. ${ }^{\circ}$ ), prorrogação (artigo 53. $\left.{ }^{\circ}, .^{\circ} 3\right)$ ].

3.3. Os procedimentos de controlo preventivo com o Decreto-Lei n. ${ }^{\circ}$ 136/2014, de 9 de setembro

Com a alteração ao RJUE efetuada pelo Decreto-Lei n. ${ }^{\circ}$ 136/2014, mantémse a referência à licença, à autorização e à comunicação prévia, mantendo-se, também o critério que está na base da mobilização de cada uma delas: a autorização fica reservada para a utilização dos edifícios; a comunicação prévia é tendencialmente mobilizada nas situações em que as regras aplicáveis são suficientemente precisas e concretas de modo a que o interessado saiba exatamente o que pode fazer; ${ }^{11}$ e as licenças ficam reservadas, tendencialmente, para as situações em que existe maior discricionariedade administrativa na apreciação do projeto, porque as regras aplicáveis não são suficientemente precisas.

A grande novidade introduzida por este diploma prende-se com a nova configuração que é dada à comunicação prévia, que passa a corresponder a "uma declaração que, desde que corretamente instruída, permite ao interessado proceder imediatamente à realização de determinadas operações após o pagamento das taxas devidas, dispensando a prática de quaisquer atos permissivos" (n. ${ }^{\circ} 2$ do artigo 34. ${ }^{\circ}$ ). Uma mera comunicação prévia, portanto.

Cumpre-se, assim, na íntegra, neste domínio, a substituição do princípio da autoridade pública pelo princípio da autorresponsabilização dos particulares: em vez de mecanismos de controlo assentes em procedimentos de autorização/licença administrativa (isto é, de controlo administrativo prévio à realização da operação urbanística), criam-se formas de controlo preventivo da responsabilidade dos próprios interessados em desenvolver a atividade urbanística que tem algum potencial de risco, e cujo desenvolvimento se mantém, por isso, dependente da observância de requisitos fixados na lei e noutros instrumentos urbanísticos aplicáveis, como os instrumentos de planeamento.

Com esta configuração, a comunicação prévia prevista no RJUE já não surge como procedimento administrativo de controlo preventivo (já que o interessado não tem de esperar por uma decisão da administração sobre a viabilidade da sua pretensão), havendo aqui apenas e exclusivamente controlos administrativos efetuados a posteriori. Trata-se, por isso, de um desvio à regra constante do n. ${ }^{\circ} 2$ do artigo 58. ${ }^{\circ}$ da Lei n..$^{\circ}$ 31/2014,

${ }_{11}$ Dizermos tendencialmente, porque este é também o procedimento mobilizável quando estão em causa operações urbanísticas com menor relevo, de que são exemplo, as piscinas associadas à edificação principal. 
de 30 de maio, ${ }^{12}$ segundo o qual "[a] realização de operações urbanísticas depende, em regra, de controlo prévio vinculado à salvaguarda dos interesses públicos em presença e à definição estável e inequívoca da situação jurídica dos interessados", correspondendo, antes, à exceção prevista no n. 3 deste mesmo normativo, que determina que "[q]uando a salvaguarda dos interesses públicos em causa seja compatível com a existência de um mero controlo sucessivo, a lei pode isentar de controlo prévio a realização de determinadas operações urbanisticas, desde que as condições de realização sejam suficientemente definidas em plano municipal".

Deixa de existir, assim, como ocorria na comunicação prévia introduzida pela Lei n. ${ }^{\circ}$ 60/2007, quer um ato expresso de rejeição da comunicação apresentada pelo interessado, quer um ato (ficcionado) de admissão: apresentada a comunicação pelo interessado (com todos os projetos) este pode iniciar imediatamente a operação (cumpridos que estejam determinados ónus, como o pagamento das taxas), ficando a verificação pela Administração do cumprimento das normas aplicáveis remetida para um momento subsequente (controlo sucessivo), e, havendo incumprimento, com aplicação de medidas de reposição da legalidade urbanística (cfr. n. ${ }^{\circ} 8$ do artigo $35 .^{\circ}$ ). A estes aspetos voltaremos mais adiante, já que por agora apenas importa reter a evolução que os procedimentos de controlo preventivo tiveram.

Resulta do afirmado anteriormente, precisamente a propósito desta evolução, que a mesma denota a preocupação constante do legislador português na procura pela simplificação dos procedimentos de controlo preventivo de atividades urbanísticas, reconhecendo que a burocracia inerente a estes procedimentos é, efetivamente, um problema que deve ser enfrentado.

\section{Os procedimentos urbanísticos: caraterização}

Vista, em traços largos, esta evolução, analisemos agora, ainda que de forma necessariamente sintética, o que carateriza cada um destes tipos de procedimento.

Tomaremos como referência a operação urbanística obras de edificação: num primeiro momento para apontar o que carateriza os procedimentos de licenciamento e de comunicação prévia destas operações e num segundo momento para analisar as vantagens e as desvantagens da comunicação prévia, de forma a averiguar se a mesma tem funcionado, efetivamente, como uma alternativa ao tradicional licenciamento.

\footnotetext{
12 A Lei n. ${ }^{\circ}$ 31/2014 aprovou entre nós as Bases Gerais da Política Pública de Solos, de Ordenamento do Território e de Urbanismo.
} 


\subsection{O procedimento de licenciamento}

i. A realização de uma obra de edificação pressupõe a elaboração dos respetivos projetos por técnicos legalmente habilitados. ${ }^{13}$ No caso de a obra estar sujeita a licenciamento, tais projetos são entregues na Câmara Municipal acompanhados do pedido de licenciamento. Verificando os serviços competentes que todos eles estão em conformidade com as normas legais e regulamentares aplicáveis, a Câmara Municipal defere a pretensão, consubstanciando o ato de deferimento a licença de construção.

Note-se, porém, que este controlo efetuado pela câmara municipal é feito em dois momentos diferenciados, correspondendo às duas fases em que o procedimento de licenciamento se desenvolve: um primeiro momento referente à apreciação do projeto de arquitetura; um segundo momento, que apenas ocorre se o projeto de arquitetura cumprir todas as normas que lhe são aplicáveis e, por isso, tiver sido aprovado, correspondente à junção dos projetos de especialidade. Nada havendo a apontar a estas é tomada a decisão final do procedimento, que consubstancia o ato de licenciamento, se for de deferimento.

Sendo a licença de construção o ato central ou o momento constitutivo deste procedimento, o mesmo, porém, apenas produz os seus efeitos permissivos depois de emitido, a requerimento do interessado, o alvará, que é o documento título da licença.

O alvará da licença de construção, assume, deste modo, a natureza de ato integrativo da eficácia do ato de licenciamento, por nada acrescentar à definição da situação jurídica do particular perante a possibilidade de realizar a operação urbanística (essa é definida com a licença de construção), apenas permitindo desencadear a sua efetiva operatividade.

O procedimento de licenciamento avança, pois, por fases: a fase da aprovação do projeto de arquitetura; a fase do deferimento do pedido de licenciamento que consubstancia a licença (que ocorre quando se conclua que os projetos de especialidade estão em conformidade com os preceitos que os regulam ${ }^{14}$ ) e a fase de emissão do alvará. Apenas depois desta emissão pode a obra iniciar-se. ${ }^{15}$

13 Integram o projeto de uma obra de edificação o projeto de arquitetura e os respetivos projetos de especialidades, integrando estes, em função do tipo de obra a executar, o projeto de estabilidade (que inclui o projeto de escavação e contenção periférica); o projeto de alimentação e distribuição de energia elétrica e o projeto de instalação de gás (quando exigível, nos termos da lei); o projeto de redes prediais de água e esgotos; o projeto de águas pluviais; o projeto de arranjos exteriores, quando exista logradouro privativo não pavimentado; o projeto de infraestruturas de telecomunicações; o estudo de comportamento térmico e demais elementos previstos em Portaria; o projeto de instalações eletromecânicas, incluindo as de transporte de pessoas e ou mercadorias; o projeto de segurança contra incêndios em edifícios e o projeto de condicionamento acústico.

14 Realce-se que não há uma decisão formal da câmara municipal sobre os projetos de especialidade como melhor se verá de seguida.

15 Sendo aprovado o projeto de arquitetura, o interessado é notificado para entregar os projetos de especialidade 
Uma análise atenta do regime atualmente em vigor permite concluir que o momento central do procedimento de licenciamento é o ato de aprovação do projeto de arquitetura, já que é nele que se controlam e definem as condições urbanísticas da realização da obra como a conformidade desta com os instrumentos de planeamento em vigor e as servidões administrativas e restrições de utilidade pública (por isso, tal apreciação corresponde a uma fase autónoma deste procedimento, que condiciona todo o andamento posterior do mesmo)..$^{16}$

Este relevo central do ato de aprovação do projeto de arquitetura resulta ainda do facto de este ser o único momento em que a câmara municipal efetua o controlo preventivo da pretensão edificatória do interessado. E isto porque, ao contrário do que sucedia tradicionalmente [em que a câmara municipal controlava/apreciava todos os projetos da obra, quer o projeto de arquitetura quer os projetos de especialidade], atualmente os projetos de especialidade não são por ela controlados.

Com efeito, segundo a lei, as declarações de responsabilidade dos autores dos projetos das especialidades constituem garantia bastante do cumprimento das normas legais e regulamentares aplicáveis a estes projetos, excluindo a sua apreciação prévia pelos serviços municipais, sem prejuízo de, em algumas situações, tais projetos estarem sujeitos a certificação, aprovação ou parecer de entidades exteriores ao município ${ }^{17}$ (entidades

num determinado prazo sob pena de caducidade daquele ato; sendo emitida a licença, o interessado tem também um prazo para requerer o respetivo alvará, sob pena de caducidade da licença. Isto significa que o procedimento de licenciamento avança por fases e sempre mediante impulso do interessado.

Por avançar por fases o interessado apenas tem de entregar, aquando do pedido de licenciamento, o projeto de arquitetura, sendo os projetos de especialidade entregues depois da aprovação deste (é dado ao particular um prazo para o efeito). A lei não impede, é certo, que o interessado junte todos os projetos em simultâneo, mas não será normal que isso aconteça porque se o projeto de arquitetura não estiver em condições de ser aprovado, o pedido é indeferido, ficando inutilizados os projetos de especialidade apresentados; se for aprovada com condições pode implicar alterações aos projetos de especialidades, o que se traduz em gastos acrescidos para o particular se já os tiver elaborado e entregue, porque terá de os alterar. Em todo o caso, quando os projetos são entregues em simultâneo (e pressupondo que os projetos de especialidade não necessitam de ser alterados), ainda assim, a câmara municipal aprecia primeiro o projeto de arquitetura e só depois de esta ser aprovada avança para a fase subsequente do procedimento, que se inicia com a entrega dos projetos de especialidade.

16 Para esta apreciação a lei exige a necessidade de consulta de entidades externas, com especial relevo para aquelas que se pronunciam em razão da localização da obra. Esta consulta é, por norma promovida pela câmara municipal. Caso as entidades a consultar pertençam à administração central, esta consulta é promovida no âmbito de uma conferência de serviços presidida pelas comissões de coordenação e desenvolvimento regional (um órgão desconcertado do Estado).

17 Algumas das entidades encarregues de controlar os projetos de especialidade são, em certas situações, inclusive, entidades privadas, consubstanciando esta solução uma privatização material dos controlos ou, como a doutrina costuma designar, um fenómeno de deslocação da responsabilidade de controlo para a esfera de privados: não um autocontrolo (como vimos acontecer com a comunicação prévia), mas um controlo efetuado por organismos externos, independentes e imparciais, oficialmente reconhecidos ou credenciados para a realização de ações de controlo e de certificação.

Neste caso o interessado passa a ter de contratar um terceiro que, de forma isenta e independente e com 
estas que procedem, precisamente, ao controlo da conformidade daqueles projetos com as normas que os disciplinam), que, por isso, devem ser obtidos. A esta solução, o DecretoLei n. ${ }^{\circ}$ 26/2010 veio acrescentar a desnecessidade de junção no processo administrativo, da aprovação ou certificação daqueles projetos de especialidades por entidade externa ou interna, conforme o legalmente estipulado, desde que sejam substituídas por termo de responsabilidade do respetivo autor (termo esse que para além de atestar que na elaboração do mesmo foi cumprida a legislação específica, assegure, caso exista previsão legal de autorização ou certificação do projeto, que a mesma já foi obtida ou está em curso), com o que se dispensa a apresentação dessa autorização ou certificação nos serviços municipais para que o procedimento possa prosseguir para a emissão do ato final (o ato de licenciamento). Isto sem prejuízo da necessidade da sua obtenção. ${ }^{18}$

Tendo em consideração o referido, percebe-se que à câmara municipal apenas cabe, no que concerne aos projetos de especialidades, garantir que os mesmos são atempadamente entregues (sob pena de caducidade do ato de aprovação do projeto de arquitetura) e objeto de consulta, aprovação, parecer ou certificação quando legalmente exigidos. Ou seja, apenas lhe cabe garantir a existência, no processo, de quem se responsabilize pelos projetos de especialidade. ${ }^{19}$

Tendo em conta o que acabámos de referir, percebe-se que a função dos municípios no âmbito dos procedimentos de licenciamento de obras de edificação é a de proceder ao controlo das condições urbanísticas da sua realização, isto é, a de proceder à verificação do cumprimento, pelas mesmas, dos instrumentos de planeamento e outras regras relativas e das regras técnicas de construção. Não lhe cabe, porém, verificar se

garantia de credibilidade, resultante de uma acreditação oficial, realiza ações de controlo preventivo dos projetos de especialidade. Pedro Gonçalves defende que estes organismos desenvolvem uma tarefa privada (verdadeira privatização material), por isso os contratos que os interessados celebram com eles são contratos privados: estes organismos independentes não atuam por delegação da entidade pública, na esfera de uma responsabilidade pública de execução, mas por atribuição do interessado, no âmbito de uma responsabilidade própria deste (que a lei lhe entregou), pelo controlo preventivo de certas atuações. Trata-se de um fenómeno de "controlos privados externos". (GONÇALVES, 2005, p. 187 e 190).

18 Mas recentemente, buscando ir mais longe na eliminação de "situações de burocracia injustificada e geradora de consumos de tempo e dinheiro que prejudicam o investimento e os cidadãos", a legislação relativa a alguns destes projetos tem vindo a evoluir a ponto de eliminar a formalidade de aprovação do projeto por estes organismos externos, bastando-se a lei com o termo de responsabilidade subscrito pelo projetista atestando a conformidade do projeto com as normas regulamentares e técnicas aplicáveis. Veja-se, a título de exemplo, o Decreto-Lei n. ${ }^{\circ}$ 96/2017, de 10 de agosto (relativo a instalações elétricas de serviço particular alimentadas pela rede elétrica de serviço público) e o Decreto-Lei n. ${ }^{\circ}$ 97/2017, de 10 de agosto (relativo a instalações de gases combustíveis em edifícios), onde deixa de haver a exigência deste prévio controlo por entidades externas, passando a responsabilidade pelo cumprimento das normas para a esfera do técnico autor do projeto.

19 Essa responsabilidade incidirá ou, nos casos legalmente previstos, sobre a entidade que o autoriza emite parecer ou o certifica ou sobre o técnico legalmente habilitado que o ateste em termo de responsabilidade. Um e outro destes documentos apresentam-se como elemento instrutório indispensável para o prosseguimento do procedimento, com vista à emissão do ato final de licenciamento. 
a obra cumpre todas as regras urbanísticas e de construção que lhe são aplicáveis, mas apenas, e no seu essencial, aquelas que se destinam a salvaguardar o correto ordenamento do território, portanto, as constantes de planos municipais e especiais de ordenamento do território, de medidas preventivas, de servidões administrativas e restrições de utilidade pública e ainda, de quaisquer outras normas legais e regulamentares relativas ao aspeto exterior e à inserção urbana e paisagística das edificações, ${ }^{20}$ bem como sobre o uso proposto.

E estes são, precisamente, os aspetos que se controlam na apreciação do projeto de arquitetura (cfr. n. ${ }^{\circ} 1$ do art. $20 .^{\circ}$ do RJUE) que, se não estiverem cumpridos determinam o indeferimento do pedido (art. $24 .^{\circ}$ do RJUE).

ii. Decorre do descrito que o ato de aprovação do projeto de arquitetura é, afinal, o único ato pelo qual, no procedimento de licenciamento, o município formula um juízo próprio e autónomo em relação à obra, ficando todos os restantes aspetos da edificação fora do seu poder de apreciação e, por isso, do âmbito da sua responsabilidade. O próprio ato final de licenciamento da sua autoria não integra qualquer juízo próprio e inovador sobre a pretensão edificatória do interessado, limitando-se a confirmar a existência de anteriores atos (isto é, a atestar que o projeto de arquitetura foi aprovado e que estão no processo todos os projetos de especialidade, respetivos termos de responsabilidade, aprovações, pareceres ou certificações se legalmente exigíveis ou o compromisso de que serão obtidos). O que significa que o ato final do procedimento (a licença) procede apenas a uma federação (global) das várias decisões parcelares tomadas ao longo do procedimento, incorporando-as, não sendo consentido à administração municipal proceder livremente, nesse momento, ao reexame dessas pronúncias.

Nisto se traduz o carácter federador das licenças urbanísticas, o qual se apresenta como uma sua característica intrínseca. ${ }^{21}$

20 O legislador coloca o foco do controlo municipal nos aspetos exteriores e na inserção urbana e paisagística das edificações, não colocando na alçada do seu controlo, os aspetos interiores. A comprova-lo está a prescrição legal de que as declarações de responsabilidade dos autores dos projetos de arquitetura, no que respeita aos aspetos interiores das edificações, constituem garantia bastante do cumprimento das normas legais e regulamentares, aplicáveis, excluindo a sua apreciação prévia. E também o facto de o legislador isentar de controlo municipal as obras de alteração no interior dos edifícios [alínea b) do n. ${ }^{\circ} 1$ do artigo $6 .^{\circ}$ do RJUE], à exceção das que ocorram em edifícios classificados [alínea d) do $n .{ }^{\circ} 2$ do artigo $4 .^{\circ}$ do RJUE].

21 Dito de outro modo, a licença corresponde a um ato complexo que engloba vários atos autónomos, sendo um deles a aprovação do projeto de arquitetura. Esta aprovação integra a categoria genérica das prédecisões, assumindo a configuração de um ato prévio que condiciona uma decisão futura (a licença), embora desprovido de efeitos permissivos (pois não é com base nesse ato que a obra se pode iniciar).

Por intermédio deste ato a Administração municipal aprecia as condições (urbanísticas) que a obra deve respeitar, decidindo sobre elas de forma definitiva por não estar previsto no decurso do procedimento uma nova pronúncia sobre estas questões. E por isso também se afirma que a aprovação do projeto de arquitetura é um ato constitutivo de direitos (pelo menos do direito a que estas questões não voltem a ser postas em causa e discutidas no decurso do procedimento de licenciamento se aquela apreciação for válida) 
iii. Resulta do afirmado que o licenciamento de uma obra de construção contém uma tramitação dotada de alguma complexidade e com alguma demora temporal: trata-se de um procedimento que tem de ser iniciado pelo particular (requerimento); tem uma fase de apreciação do projeto da arquitetura (antecedido de consulta de entidades que, em função da localização da obra, se tenham de pronunciar sobre ela); apresentados os projetos de especialidade (acompanhados de aprovação, parecer ou certificação de entidades exteriores quando exigíveis ou termo de responsabilidade dos respetivos autores), o pedido é deferido (consubstanciando a licença); e termina com a emissão do alvará (o qual tem de ser requerido pelo interessado no prazo de um ano a contar da notificação da licença, prazo esse que pode ser prorrogado por mais um ano e pressupõe o pagamento das taxas urbanísticas e demais encargos ${ }^{22}$ ), sob pena de caducidade da licença.

Trata-se, como se pode verificar, de uma tramitação complexa e longa, sendo certo que a atividade não se pode iniciar (a obra não pode ser executada) sem que exista uma decisão da Administração, que tem de ser expressa (a falta de decisão, não vale como deferimento: para que a decisão seja emitida terá o interessado, neste caso, de lançar mão das vias adequadas, designadamente a via judicial com vista a intimar a câmara municipal para a prática de ato legalmente devido (a decisão sobre o pedido de licenciamento). Como determina o n. 3 do artigo 58. ${ }^{\circ}$ da Lei n. ${ }^{\circ} 31 / 2014$, terá de ser emitido um ato administrativo que, na sequência de um juízo prévio sobre a salvaguarda dos interesses públicos em presença, proceda à "definição estável e inequívoca da situação jurídica dos interessados".

Ora uma das principais críticas ao procedimento de licenciamento (enquanto procedimento de controlo preventivo da atividade edificatória), é, precisamente o longo e excessivo caminho que é necessário percorrer até que o interessado possa iniciar a obra, o que se apresenta como um "custo de contexto" para o promotor.

Daí que, como explicado antes, o legislador tenha introduzido, pelo menos em relação a alguns tipos de obras, o procedimento da mera comunicação prévia, visando uma maior celeridade do processo urbano e uma maior económica de meios. Vejamos, em traços largos, o que a carateriza.

sendo vinculativo para a câmara municipal aquando da deliberação final (isto é, da prolação do ato de licenciamento).

22 O não pagamento das taxas é motivo de indeferimento da emissão do alvará, sem o qual a obra não pode iniciar-se. 


\subsection{Comunicação prévia}

i. A comunicação prévia, com a configuração prevista na versão atual do RJUE, não é um procedimento de controlo preventivo no sentido anteriormente apontado, isto é, no sentido de o particular, para levar a cabo a sua atividade, necessitar de aguardar por uma apreciação da Administração sobre os projetos apresentados e por uma decisão sobre os mesmos (ainda que ficcionada). E isto na medida em que, nos termos do n. ${ }^{\circ}$ 2 do artigo $34 .^{\circ}$, esta comunicação consiste, agora, "numa declaração que, desde que corretamente instruída, permite ao interessado proceder imediatamente à realização de determinadas operações urbanísticas após o pagamento das taxas devidas, dispensando a prática de quaisquer atos permissivos".

Assim, o interessado comunica à câmara municipal que vai realizar a obra, instruindo-a com todos estes elementos necessários para a identificação da operação e a sua localização: todos os projetos (de arquitetura e de especialidade, estes acompanhados das certificações aprovações e certificações legalmente exigidos ou termo de responsabilidade de que serão obtidas) e demais elementos regulamentarmente exigidos. Segue-se uma fase de saneamento administrativo, para verificar se todos esses elementos estão no processo (e que são imprescindíveis para que o controlo sucessivo que a Administração terá de efetuar), findo o qual o interessado pode pagar as taxas (por autoliquidação) e iniciar a obra.

Isto não significa, porém, ao contrário do que se possa pensar, que a operação deixa de ser objeto de controlo municipal nem, muito menos, que deixa de haver um dever de o órgão competente impedir que seja levada a cabo a operação que não cumpra as normas legais ou regulamentares em vigor. ${ }^{23}$ Com efeito, não só aquele dever de apreciação existe (caso contrário não tem o órgão como saber se a pretensão cumpre ou não as normas aplicáveis), como existe ainda um dever acrescido de impedir (inviabilizar) que a operação ilegal se execute. ${ }^{24}$

A única coisa, assim, que muda (e não é pouco) é o facto de o particular não ter de esperar por aquela apreciação (e decisão) para iniciar e executar a operação, ou seja, não necessitar para o efeito de "quaisquer atos permissivos".

23 E isto porque não há, aqui, qualquer liberalização da realização da operação urbanística.

24 De facto, o artigo $70 .^{\circ}$ do RJUE determina, na alínea d) do $n .^{\circ}$, a responsabilidade solidária com o município, em caso de dolo ou culpa grave, dos membros da câmara municipal quando não promovam as medidas necessárias à reposição da legalidade, nos termos do disposto no n. ${ }^{\circ} 8$ do artigo $35 .^{\circ}$. 
A comunicação prévia corresponde, deste modo, verdadeiramente, a uma isenção de controlo prévio (cfr. n. 3 do artigo 58. ${ }^{\circ}$ da Lei de Bases de 2014), remetendo, por isso - por não ser exigida a prática de qualquer ato permissivo para que o interessado execute a sua pretensão -, as referidas operações para um controlo sucessivo.

Isto significa que se a pretensão não cumprir as normas aplicáveis, não tem agora a Administração como rejeitar a pretensão para impedir que a operação se inicie, tendo, antes, de reagir à mesma, se ela começar a ser executada. O que implica que a Administração deve atuar, nestes casos, preventivamente e o mais antecipadamente possível, apreciando, informalmente, a pretensão de imediato, assim que a comunicação lhe seja feita (para o que tem de vir instruída com todos os elementos que permitam conhecer a operação), de forma a verificar se ela cumpre todas as normas aplicáveis e, caso tal não aconteça, obstando à sua execução, adotando o mais antecipadamente possível as medidas adequadas para o efeito.

Nos casos em que, da apreciação feita, a Administração conclua que a pretensão apresenta desconformidades com as normas legais ou regulamentares aplicáveis ou não foi precedida das consultas obrigatórias ou está em desconformidade com pronúncias vinculativas, a lei determina que a câmara municipal reaja, impedindo a execução daquela pretensão "em sede de fiscalização sucessiva".

Não é, assim, agora possível, como antes (quando estava em causa uma comunicação prévia com prazo), rejeitar a pretensão e, assim, impedir que ela se inicie; apenas poderá reagir, se ela se iniciar efetivamente.

Temos defendido, porém, que não está a entidade administrativa impedida (está até obrigada a fazê-lo por força dos princípios da cooperação e da boa-fé procedimental previstos no artigo $60{ }^{\circ}$ do CPA) de apreciar o projeto ${ }^{25}$ - informalmente claro no sentido de que não há uma fase própria para que tal aconteça como existe no licenciamento assim que ele lhe é apresentado através da comunicação prévia e de informar de imediato os interessados dessas desconformidades bem como das consequências que daí advirão, caso tais desconformidades não sejam entretanto corrigidas: o desencadeamento das medidas previstas no . $^{\circ} 8$ do artigo $35 .^{\circ}$ (a mais adequada a impedir que a obra seja levada a cabo é o seu embargo imediato). Momento que pode até ser regulamentado, ao abrigo do princípio da adequação procedimental previsto no CPA, nos Regulamentos Municipais de Urbanização e de Edificação.

Assim, e em suma, sendo apresentada uma comunicação prévia à Administração - a qual permite que o interessado realize imediatamente a operação urbanística sem dependência de quaisquer atos permissivos municipais, desde que tenha

25 Trata-se aqui, como no procedimento de licenciamento, apenas a apreciação do projeto de arquitetura. 
pago as taxas -, deve ser feita, de imediato, pelos serviços municipais, uma apreciação técnica do projeto e, detetadas desconformidades com as normas legais e regulamentares, devem também de imediato ser desencadeadas todas as medidas necessárias para evitar que a operação se concretize (execute), sem prejuízo de, de forma preventiva e antecipada, se informar o interessado dessas desconformidades bem como do desencadeamento das medidas de reposição da legalidade adequadas a impedir a execução da operação, caso ele as não corrija entretanto.

ii. Se compararmos os trâmites a que o interessado tem de dar cumprimento no procedimento de licenciamento e aqueles que tem de cumprir no âmbito da comunicação prévia, dúvidas não restam de que neste último caso prevalecem os tempos dos privados em detrimento dos tempos da Administração: esta não está dispensada de controlar o cumprimento, por parte dos projetos, das normas legais e regulamentares que também controla nos procedimentos de licenciamento; não tem é o interessado de aguardar por esse controlo para iniciar a obra: efetuado por si próprio um autocontrolo preventivo do cumprimento dessas normas, paga as taxas e inicia de imediato a construção.

$\mathrm{O}$ quadro comparativo entre o procedimento de licenciamento e a comunicação prévia de obras que juntamos de seguida comprova bem a diferença, em termos se maior simplificação e celeridade procedimental, desta em relação àquele.

\begin{tabular}{|c|c|}
\hline Licenciamento & Comunicação prévia \\
\hline $\begin{array}{l}\text { Iniciativa: requerimento devidamente } \\
\text { instruído e com entrega do projeto de } \\
\text { arquitetura }\end{array}$ & $\begin{array}{l}\text { Iniciativa: requerimento devidamente } \\
\text { instruído e com entrega de todos } \\
\text { os projetos (de arquitetura, de } \\
\text { especialidades acompanhados de termos } \\
\text { de responsabilidade e de autorizações, } \\
\text { pareceres ou certificações legalmente } \\
\text { exigidos. A entrega destas pode ser } \\
\text { dispensada se o técnico se responsabilizar } \\
\text { que a obterá); e com a pronúncia das } \\
\text { entidades que tenham de se pronunciar } \\
\text { sobre o projeto de arquitetura em função } \\
\text { da localização que tenha lugar }\end{array}$ \\
\hline $\begin{array}{l}\text { Saneamento: para verificar a regularidade } \\
\text { formal e instrutória do processo }\end{array}$ & $\begin{array}{l}\text { Saneamento: para verificar a regularidade } \\
\text { formal e instrutória do processo }\end{array}$ \\
\hline $\begin{array}{l}\text { Instrução: consulta de entidades que } \\
\text { tenham de se pronunciar em função da } \\
\text { localização }\end{array}$ & - \\
\hline
\end{tabular}




\begin{tabular}{|l|l|}
\hline $\begin{array}{l}\text { Aprovação do projeto de arquitetura } \\
\text { notificada ao interessado para que entregue } \\
\text { os projetos de especialidade }\end{array}$ & - \\
\hline $\begin{array}{l}\text { Entrega de projetos de especialidade } \\
\text { acompanhados de termos de respon- } \\
\text { sabilidade e de autorizações, pareceres } \\
\text { ou certificações legalmente exigidos (a } \\
\text { entrega destas pode ser dispensada se o } \\
\text { técnico se responsabilizar que a obterá) }\end{array}$ & \\
\hline $\begin{array}{l}\text { Licença de construção notificada ao } \\
\text { interessado }\end{array}$ & \\
\hline $\begin{array}{l}\text { Requerimento do alvará com pagamento } \\
\text { das taxas devidas }\end{array}$ & Pagamento das taxas \\
\hline Emissão do Alvará & Início da obra \\
\hline Início da obra & \\
\hline
\end{tabular}

iii. Em termos de balanço final podemos afirmar que com a nova configuração, a comunicação prévia corresponde a uma forma de privatização de responsabilidades públicas e de reforço de responsabilidades privadas. Com efeito, o particular antes de iniciar a obra tem, ele próprio, de verificar, preventivamente, se cumpre todas as regras em vigor (responsabilizando-se por isso) e efetua tarefas instrutórias que em regra seriam da responsabilidade de administração (como a consulta das entidades que têm de se pronunciar sobre o projeto de arquitetura em função da localização).

Desta perspetiva a comunicação prévia tem vantagens para a Administração, vantagens essas que se traduzem numa diminuição dos seus custos no controlo preventivo da atividade privada: isto porque a sua intervenção preventiva é, como vimos, mínima, limitada a um saneamento muito circunscrito.

Porém a comunicação prévia aumenta os custos no controlo administrativo sucessivo, que tem necessariamente que ocorrer (com a agravante de esse controlo dever ser o mais célere possível para evitar que a edificação eventualmente desconforme com a legalidade vigente se consolide, porque entretanto já se iniciou).

Da perspetiva dos interessados, se a comunicação prévia tem vantagens do ponto de vista dos tempos de controlo (que deixam de ser feitos pela Administração, passando a ser feita por eles próprios: feitos estes controlos o interessado apresenta a comunicação prévia à Administração, paga as taxas e inicia as obras), apresenta-se, em contrapartida, como uma maior "sobrecarga" para estes (quer do ponto de vista procedimental, tendo de efetuar tarefas, designadamente instrutórias, que caberiam à Administração quer das responsabilidades que assume). 
Não admira, por isso, que as comunicações prévias tenham sido assumidas pelos interessados como figuras non gratas não só pelos custos procedimentais e das responsabilidades acrescidas que assumem, mas também, principalmente, pela incerteza e insegurança que acarretavam (já que nem sempre as normas mobilizáveis são claras ou isentas de dúvidas e, portanto, não tem o interessado a certeza de que, em sede de controlo sucessivo, a obra não seja embargada porque a interpretação por si feita das normas aplicáveis não coincide com a interpretação da Administração).

Talvez por isso, o legislador veio permitir ao interessado, nas situações em que a comunicação prévia é mobilizável, que este possa optar pelo regime do licenciamento. Solução que lhe permite, por um lado, fasear o procedimento e, deste modo, fasear as despesas envolvidas nestes processos (não tem o interessado de assumir, logo à partida, o encargo da elaboração de todos os projetos), e por outro lado, lhe permite avançar com base em pronuncias expressas da administração sobre a conformidade da operação urbanista com os interesses públicos em causa que, por esse motivo definem de forma estável e inequívoca a sua situação jurídica, o que lhe dá maior segurança e estabilidade. $^{26}$

A maior dúvida que esta a mera comunicação prévia de obras de edificação acarreta prende-se com a tutela das posições jurídicas subjetivas de outros particulares cujos interesses possam ser abalados pela realização de operações urbanísticas desconformes com a legalidade urbanística, podendo questionar-se se será suficiente o n. ${ }^{\circ}$ 8 do artigo $35 .^{\circ}$ e os poderes de fiscalização e de adoção de medidas de tutela de legalidade urbanística por parte da câmara municipal.

Isto porque, vedado que está o recurso a meios impugnatórios de atos e os respetivos meios cautelares, por inexistir um ato administrativo, têm aqueles outros particulares de buscar outras vias, menos óbvias, de reação, como uma ação dirigida à câmara municipal para que esta utilize os seus poderes de inviabilização da obra nos termos do n. ${ }^{\circ} 8$ do artigo $35^{\circ}$ ou uma ação dirigida ao dono da obra com vista a que este se abstenha de erigir em desconformidade com regras urbanísticas de cumprimento obrigatório. $^{27}$

Poderá também questionar-se se está devidamente assegurado o acesso por terceiros à informação sobre as operações sujeitas a comunicação prévia, ainda que esta questão não tenha passado despercebida ao legislador ao manter o dever de publicitar a comunicação prévia (artigo $12^{\circ}$ ) e ao prever a disponibilização diária, através da

\footnotetext{
26 Caso, no exercício deste poder de controlo, a decisão proferida pela Administração seja inválida, ainda assim o particular não fica desprotegido: por ter atuado confiando na decisão da Administração poderá, se tiver danos, pode imputá-los àquela entidade (artigo $70 .^{\circ}$ sobre a responsabilidade da Administração por prejuízos resultantes de operações urbanísticas executadas com base em atos de controlo prévio ilegais).

27 Sobre esta via cfr. Fernanda Paula Oliveira (2017, p. 675 et seq.).
} 
plataforma eletrónica, das operações objeto de comunicação prévia, o que garantirá que esta informação possa ser acedida por todos.

Coimbra, fevereiro de 2020.

\section{Referências}

GONÇALVES, Pedro António Pimenta Costa. Entidades privadas com poderes públicos: o exercício de poderes públicos de autoridade por entidades privadas com funções administrativas. Coimbra: Almedina, 2005. p. 186, 201 et seq.

OLIVEIRA, Fernanda Paula. A ação sobre (alguns) comportamentos: breves considerações. In: GOMES, Carla Amado; NEVES, Ana Fernanda; SERRÃO, Tiago. (coord.). Comentários à revisão do ETAF e do CPTA. 3. ed. Lisboa: AAFDL Editora, 2017. p. 663-696. p. 675 et seq.

PORTUGAL. Decreto-Lei n. ${ }^{\circ}$ 4/2015. No uso da autorização legislativa concedida pela Lei n. ${ }^{\circ}$ 42/2014, de 11 de julho, aprova o novo Código do Procedimento Administrativo. Diário da República, Lisboa, $1^{\mathrm{a}}$ série, n. ${ }^{\circ}$ 4, p. 50.87, 7 jan. 2015. Disponível em: https://dre.pt/application/ conteudo/66041468.

PORTUGAL. Decreto-Lei n. ${ }^{\circ}$ 96/2017. Estabelece o regime das instalações elétricas particulares. Diário da República, Lisboa, $1^{\mathrm{a}}$ série, n. ${ }^{\circ}$ 154, p. 4.654-4.663, 10 ago. 2017. Disponível em: https:// dre.pt/application/conteudo/107987277.

PORTUGAL. Decreto-Lei n. ${ }^{\circ}$ 97/2017. Estabelece o regime das instalações de gases combustíveis em edifícios. Diário da República, Lisboa, $1^{\text {a }}$ série, n. ${ }^{\circ}$ 154, p. 4.663-4.672, 10 ago. 2017. Disponível em: https://dre.pt/application/conteudo/107987278.

PORTUGAL. Decreto-Lei n. ${ }^{\circ}$ 136/2014. Procede à décima terceira alteração ao Decreto-Lei n. ${ }^{\circ}$ 555/99, de 16 de dezembro, que estabelece o regime jurídico da urbanização e edificação. Diário da República, Lisboa, $1^{\mathrm{a}}$ série, n. ${ }^{\circ}$ 173, p. 4.809-4.827, 9 set. 2014. Disponível em: https://dre.pt/ application/conteudo/107987278.

PORTUGAL. Decreto-Lei n. ${ }^{\circ}$ 177/2001. Altera o Decreto-Lei n. ${ }^{\circ}$ 555/99, de 16 de Dezembro, que estabelece o regime jurídico da urbanização e da edificação. Diário da República, Lisboa, $1^{a}$ série, n. ${ }^{\circ}$ 129, p. 3.297-3.334, 4 jun. 2001. Disponível em: https://dre.pt/application/conteudo/331257.

PORTUGAL. Decreto-Lei n. ${ }^{\circ}$ 555/99: consolidado. Regime jurídico da urbanização e edificação. Diário da República, Lisboa, $1^{\text {a }}$ série, n. ${ }^{0}$ 291, 16 dez. 1999. Disponível em: https://dre.pt/ web/guest/legislacao-consolidada/-/lc/124778876/202012142318/diploma?did=34567875\&_ LegislacaoConsolidada_WAR_drefrontofficeportlet_rp=indice\&q=555\%2F99.

PORTUGAL. Lei n. ${ }^{\circ}$ 31/2014. Lei de bases gerais da política pública de solos, de ordenamento do território e de urbanismo. Diário da República, Lisboa, $1^{\mathrm{a}}$ série, n. ${ }^{\circ}$ 104, p. 2.988-3.003, 30 maio 2014. Disponível em: https://dre.pt/application/conteudo/25345938. 
PORTUGAL. Lei n. ${ }^{\circ}$ 60/2007. Procede à sexta alteração ao Decreto-Lei n. ${ }^{\circ}$ 555/99, de 16 de Dezembro, que estabelece o regime jurídico da urbanização e edificação. Diário da República, Lisboa, $1^{\text {a }}$ série, n. ${ }^{\circ} 170$, p. 6.258-6.280, 4 set. 2007. Disponível em: https://dre.pt/application/ conteudo/640138.

UNIÃO EUROPEIA. Parlamento Europeu. Directiva 2006/123/CE do Parlamento Europeu e do Conselho de 12 de Dezembro de 2006, relativa aos serviços no mercado interno. Jornal Oficial da União Europeia, Bruxelas, 27 dez. 2006. Disponível em: https:/eur-lex.europa.eu/legal-content/ $\mathrm{PT} / \mathrm{TXT} / \mathrm{PDF} /$ ?uri=CELEX:32006L0123\&from=PT. 
